\title{
REPRESENTASI SPORTIVITAS DALAM IKLAN NISSIN CUP NOODLES
}

\author{
N.L.P.T. RIKASANTII, J. YUSHARIO ${ }^{2}$, K.A.E. PURWANTI ${ }^{3}$ \\ ${ }^{123}$ Jurusan Pendidikan Bahasa Jepang , Universitas Pendidikan Ganesha, Singaraja, Bali \\ e-mail: trisha@undiksha.ac.id joelham@undiksha.ac.id ayu.elvira@undiksha.ac.id
}

\begin{abstract}
Abstrak
Penelitian ini bertujuan untuk memaparkan makna representasi sportivitas pada iklan Nissin Cup Noodle yang dibuat oleh pihak Nissin dan bekerja sama dengan dua atlet tenis lapangan Nishikori Kei, Osaka Naomi, dan anime Prince of Tennis. Penelitian ini menggunakan analisis kualitatif. Teknik analisis data yang digunakan adalah teknik observasi. Objek penelitian ini adalah tanda-tanda yang menunjukkan representasi sportivitas pada iklan tersebut. Tanda yang ditemukan peneliti adalah tanda atlet Nishikori dan Osaka sedang berlatih dan tanda atlet Nishikori Kei yang berjabat tangan dengan tokoh anime Prince of Tennis bernama Echizen Ryoma yang di damping oleh atlet Osaka Naomi dan Tezuka Kunimitsu (tokoh dari anime Prince of Tennis).
\end{abstract}

Kata kunci: Iklan, Tokoh anime Prince of Tennis, Representasi sportivitas.

\begin{abstract}
This research purpose are to explain the meaning of representative sportsmanship in Nissin Cup Noodle advertisement which made by Nissin that cooperate with two tennis athlete, Kei Nishikori, Naomi Osaka, and anime Prince of Tennis. This research are using qualitative analysis. The data analysis technique used is the observation technique. The object of research are signs that represent the sportsmanship representative of the advertisement. The signs that found by researcher are a sign of athlete Kei Nishikori and Naomi Osaka are training and a sign of athlete Kei Nishikori whom shakes hands with Ryoma Echizen, the character of anime Prince of Tennis accompanied by athlete Naomi Osaka and Kunimitsu Tezuka (character from anime Prince of Tennis).
\end{abstract}

Keywords : Ad, Prince of Tennis anime characters, Representative sportsmanship.

\section{Pendahuluan}

Iklan audio visual merupakan bentuk promosi dalam memperkenalkan dan memberikan pengetahuan serta ajakan langsung kepada calon konsumen untuk membeli produk. Iklan audio visual menyampaikan pesan secara persuasif dengan membangun presepsi konsumen dengan kuat dan menjangkau khalayak secara luas. Hal tersebut akan tersampaikan dengan baik jika dirancang oleh personel komunikasi dengan memperhatikan isi pesan, struktur dan format pesan, termasuk iklan audio visual.

Adapun iklan yang akan penulis bahas yaitu nissin cup noodles. Iklan ini dirilis pada tanggal 14 januari 2019 yang dibuat oleh pihak Nissin Food Product (Basell, 2019). Adapun kelebihan iklan nissin cup noodles dengan bekerja sama dengan The prince of tennis dengan menampilkan Naomi Osaka dan Nishikori sedang berlatih yang ditayangkan dalam bentuk anime. Kelebihan dari iklan tersebut membuat penulis tertarik untuk mencari tanda tanda representasi spotivitas yang terdapat dalam iklan. Selain itu, representasi merupakan perbuatan mewakili, keadaan diwakili, apa yang mewakili, atau perwakilan (Depdiknas, 2008: 1167). Sedangkan sportivitas diidentifikasikan sebagai perilaku yang menunjukan sikap hormat dan adil terhadap orang lain serta sikap menerima dengan baik apapun hasil dari suatu pertandingan (Beller\&Stoll, 1993: 75). Jadi representasi sportivitas merupakan perbuatan yang mewakili sebuah sikap hormat dan adil terhadap orang lain serta sikap menerima dengan baik apapun hasil dari suatu pertandingan.

Dari pendahuluan tersebut dapat menghasilkan rumusan masalah : bagaimana representasi sportivitas dalam iklan nissin cup noodles? 


\section{Metode}

Dalam penelitian ini, digunakan metode analisis kualitatif. Metode ini adalah metode pengambilan sumber datanya dilakukan secara purposive Sugiyono (2009: 15). Analisis data dengan metode ini bersifat induktif dan cenderung subjektif. Sumber data pada penelitian ini adalah video iklan Nissin Cup Noodle. Objek penelitiannya adalah representasi sportivitas yang terdapat pada iklan tersebut.

Teknik yang digunakan dalam penelitian ini menggunakan teknik observasi. Langkah awal adalah mengobservasi iklan untuk menemukan tanda representasi sportivitas pada iklan tersebut. Dalam pelaksanaannya, menonton dan mencatat tanda-tanda yang muncul pada iklan tersebut. Selanjutnya, memilah tanda yang menunjukkan representasi sportivitas yang kemudian akan dianalisis.

\section{Hasil dan Pembahasan}

Dengan mengambil sudut pandang makna representatif sportivitas dan teori Roland Barthes, ditemukan dua tanda representatif sportivitas yang ada di iklan ini. Kedua tanda tersebut adalah.

\section{Osaka.}

1. Atlet Nishikori dan Osaka berlatih.

2. Atlet Nishikori berjabat tangan dengan Echizen yang didampingi oleh Tezuka dan

Iklan ini menceritakan tentang persiapan atlet tenis Nishikori Kei dan Osaka Naomi untuk mewakili Jepang di ajang Turnamen Grand Slam. Persiapan itu dimulai dengan munculnya seorang pelatih di atas kapal pesiar yang mengangkut Nishikori, Osaka, dan tokoh dalam anime Prince of Tennis. Pelatih itu pun memutuskan untuk melatih Nishikori dan Osaka dengan menu latihan bernama Australia spesial agar mereka siap bertanding di turnamen Grand Slam.

Scene selanjutnya, mereka sudah berada di lapangan tenis untuk berlatih. Pada scene ini, sang pelatih meminta agar Osaka dan Nishikori memenangkan satu game dalam permainan satu lawan dua. Nishikori dan Osaka masing-masing harus melawan dua orang. Setelah mendekati 100 game, Nishikori dan Osaka merasa kelelahan. Saat itu juga, Osaka dan Nishikori mengingat apa yang sudah mereka pelajari selama latihan dan hal itu menjadikan mereka semakin kuat. Adegan akhirnya adalah Nishikori dan Osaka yang berjabat tangan dengan tokoh Prince of Tennis (Tezuka dan Echizen) lalu pergi dengan helikopter yang menjemputnya.

Pada bagian pembahasan, akan dibagi menjadi dua bagian sesuai dengan pembagian pada hasil yang didapat.

1. Atlet Nishikori dan Osaka berlatih.
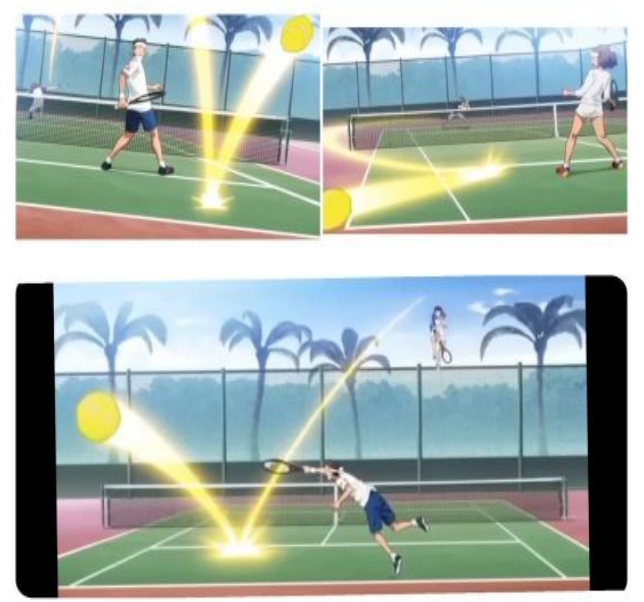

Gambar 1. Nishikori dan Osaka sedang bertanding. 

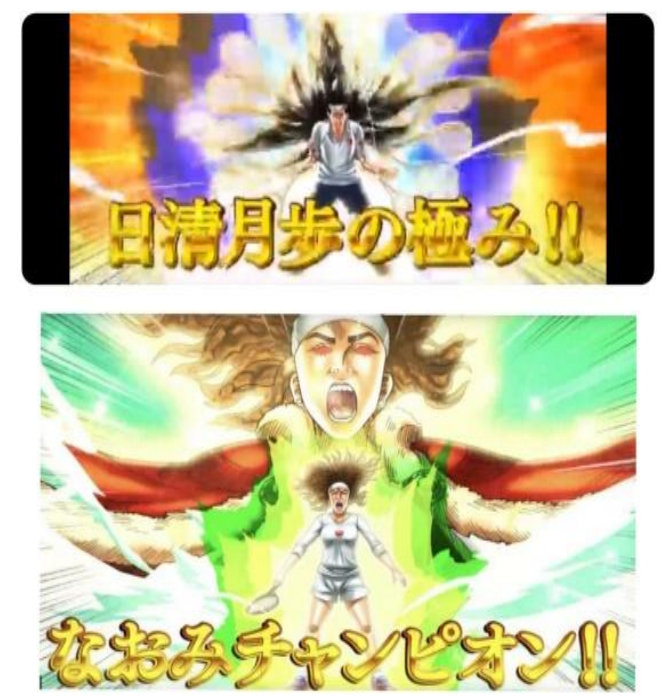

Gambar 2. Nishikori dan Osaka mengeluarkan kekuatan.

Setelah pelatih meminta mereka untuk bertanding satu lawan dua. Nishikori dan Osaka harus melawan dua orang secara bergantian. Pada gambar 1, Nishikori dan Osaka kewalahan dan tidak bisa lagi menahan serangan lawan. Namun, pada gambar 2 Nishikori dan Osaka menjadi semakin kuat dan mengalahkan lawannya. Berdasarkan penelitian yang dilakukan oleh Vallerand dkk. (1996: 93) dikutip dari salah satu faktor yang mempengaruhi prilaku sportif adalah Komitmen penuh pada keikutsertaan. Maksudnya adalah ketika seseorang memutuskan untuk mengikuti suatu pertandingan atau latihan, seseorang harus dapat mempelajari kesalahan, berusaha untuk mengatasinya dan bertahan hingga akhir. Hal ini juga yang dilakukan oleh Nishikori dan Osaka. Walaupun mereka sudah terdesak oleh lawan, tetapi mereka tetap berusaha bertahan dan mengingat apa yang mereka pelajari selama latihan hingga akhirnya dapat mencetak poin.

2. Atlet Nishikori berjabat tangan dengan Echizen yang didampingi oleh Tezuka dan Osaka.

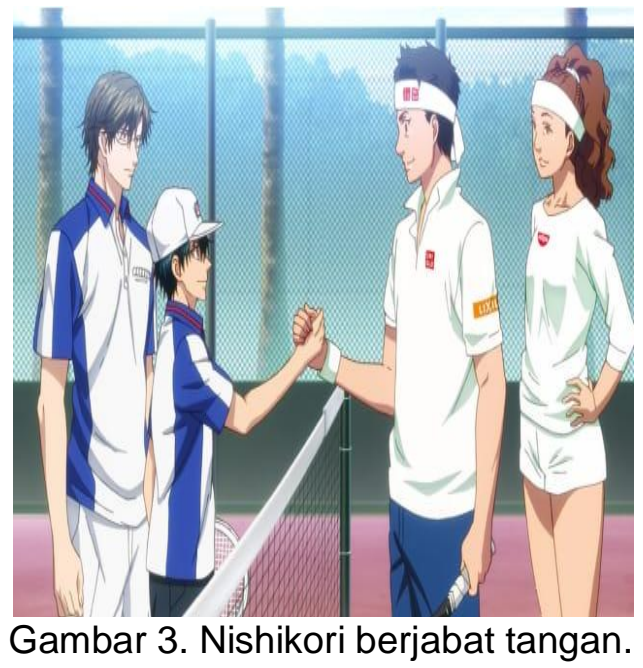

Pada gambar tampak adegan Nishikori berjabat tangan dengan Echizen (laki-laki yang mengenakan topi) didampingi oleh Osaka dan Tezuka (laki-laki yang mengenakan kacamata). Mereka tampak tersenyum satu sama lain. Adegan ini menampakkan kesan bahwa mereka tidak menyesal telah bertanding satu sama lain. Seperti yang diutarakan Beller\&Stoll (1993: 75), "sportivitas diidentifikasikan sebagai perilaku yang menunjukan sikap hormat dan adil terhadap orang lain serta sikap menerima dengan baik apapun hasil dari suatu pertandingan“. 
Dari adegan ini dapat kita pelajari bahwa menjabat tangan lawan setelah pertandingan usai merupakan representasi sportivitas.

\section{Simpulan dan Saran}

Setelah menganalisis tanda representasi sportivitas pada iklan Nissin Cup Noodle, terdapat dua tanda yang merupakan representasi sportivitas. Kedua tanda tersebut adalah :

1. Atlet Nishikori dan Osaka berlatih. Osaka.

2. Atlet Nishikori berjabat tangan dengan Echizen yang didampingi oleh Tezuka dan

Dalam iklan ini, produsen ingin menyampaikan makna sportivitas yang tersirat dari adegan latihan kedua atlet yang berusaha untuk menganalisis dan memperbaiki kesalahannya. Juga ketika kedua atlet berjabat tangan setelah selesai latihan. Dengan menampilkan atlet Nishikori dan Osaka dalam versi anime dan bekerja sama dengan anime tenis terkenal, produsen yakin dapat menyampaikan makna sportivitas dalam iklan tersebut.

\section{Daftar Pustaka}

https://kbbi.web.id/representasi.html. Diakses 23 Mei 2020

- Kamus Besar Bahasa Indonesia.[online]. Tersedia di https://kbbi.web.id/sportivitas.html. Diakses 23 Mei 2020

Baseel, Casey. 2019. Cup Noodle maker apologizes for pale-skinned depiction of Naomi Osaka in anime ad [video]. https://soranews24.com/2019/01/23/cup-noodle-makerapologizes-for-pale-skinned-depiction-of-naomi-osaka-in-anime-ad 【video】. Diakses 21 juni 2020.

Beller, J. M. \& Stoll, S. K. (1993). Sportmanship: An Antiquated Concept. (Journal of Physical Education, Recreation \& Dance). Diakses 23 Mei 2020.

Sugiyono, 2009. Metode Penelitian Kuantitatif, Kualitatifdan R\&D, Bandung : Alfabeta. Diakses 21 juni 2020.

Vallerand, dkk. 1996. Toward a Multidimensional definition of sportsmanship. (Journal of applied sport psychology). Diakses 21 juni 2020.

DATA IKLAN

Nissin Cup Noodle : Prince of Tennis

Sutradara : Nissin Foods Holdings Co.,Ltd.,

Rilis : 14 Januari 2019

Negara : Jepang 